une revue Gallia

Rhône-Alpes | 2007

\title{
Saint-Joseph
}

Grange Blanche

\section{Catherine Coquidé}

\section{(2) OpenEdition}

12 Journals

Édition électronique

URL : http://journals.openedition.org/adlfi/6980

ISSN : 2114-0502

Éditeur

Ministère de la culture

Référence électronique

Catherine Coquidé, "Saint-Joseph », ADLFI. Archéologie de la France - Informations [En ligne], RhôneAlpes, mis en ligne le 01 mars 2007, consulté le 01 mai 2019. URL : http://journals.openedition.org/ adlfi/6980

Ce document a été généré automatiquement le 1 mai 2019.

(c) Ministère de la Culture et de la Communication, CNRS 


\title{
Saint-Joseph
}

\author{
Grange Blanche
}

\section{Catherine Coquidé}

Identifiant de l'opération archéologique : 229347

Date de l'opération : 2007 (SD)

1 Les sondages d'évaluation du potentiel archéologique d'un futur lotissement ont permis de préciser le tracé de l'aqueduc antique du Gier au sortir du contournement du vallon de Vaille et avant son passage en tunnel sous la Bessonière. Relativement bien conservé, alternant une section intacte et d'autres révélant un arasement variable de la voûte, il aborde ce changement de direction d'une façon plus rectiligne que celle envisagée au départ.

2 Le peu de recul induit par les sondages limite les observations liées à la construction. Les mesures disponibles sont conformes à la norme admise pour cet ouvrage. Notons seulement que deux césures de montage de la voûte sont perçues à $6 \mathrm{~m}$ d'intervalle et que les matériaux de construction pourraient provenir de la tranchée d'installation, au moins partiellement. Là où la voûte est conservée, un vide de $0,25 \mathrm{~m}$ et plus est encore accessible. Sur les quatre sondages concernés par le tracé, trois révèlent un piquage postérieur à son abandon en tant que conduite desservant Lugdunum. Il s'agit pour deux d'entre eux d'un caniveau superficiel de petit module et d'une saignée non aménagée, beaucoup plus importante, entaillant profondément le rocher. Le troisième est beaucoup plus original puisqu'il prend la forme d'une ouverture ménagée sur l'extrados à un point de faiblesse (une césure de montage de la voûte). Cet accès profitait d'un bouchage non maçonné et soigné composé de dalles et de blocs amovibles. Le scellement par la colluvion de pente et le passage postérieur d'un drain caillouteux indiquent une utilisation éventuellement antérieure à l'époque contemporaine.

3 Les sondages d'évaluation concernaient l'ensemble des parcelles disponibles et se sont également attaché à reconnaître les abords en amont de l'ouvrage. Pour la première fois, le passage de la tranchée supérieure, probable doublon abandonné de l'aqueduc, a été 
mise au jour en sous-sol. De $13 \mathrm{~m}$ à $14 \mathrm{~m}$ plus haute (niveau de surface), elle prend la forme d'une entaille dans le rocher large de 1,30 m (hors érosion superficielle). Elle est donc plus étroite que la conduite qui lui fera suite. L'arrivée massive d'eau d'infiltration a empêché d'appuyer les observations stratigraphiques et de reconnaître le fond avec précision. Son comblement recèle néanmoins de nombreuses tegulae dont la présence reste inexpliquée.

4 À $100 \mathrm{~m}$ vers l'amont sont également mis au jour les abords d'une implantation antique signalée par un niveau charbonneux accompagné de mobilier céramique. Ce niveau tapisse le rocher et occupe le fond d'une dépression encore inondable. Le résultat des sondages semble indiquer que l'occupation principale se situe sur le replat juste au nord de l'emprise. Des prospections récentes avaient d'ailleurs signalé la présence d'un site à cet endroit. La chronologie, étagée depuis les $\mathrm{II}^{\mathrm{e}} \mathrm{s}$. et $\mathrm{III}^{\mathrm{e}} \mathrm{s}$. (terminus post quem) jusqu'aux $\mathrm{IV}^{\mathrm{e}} \mathrm{s}$ et $\mathrm{V}^{\mathrm{e}} \mathrm{s}$. apr. J.-C., ne permet pas d'affirmer la contemporanéité de cette occupation avec l'aqueduc dont l'utilisation n'est avérée, à ce jour, qu'aux I ${ }^{\mathrm{er}} \mathrm{s}$. et II ${ }^{\mathrm{e}} \mathrm{s}$.

\section{INDEX}

Index géographique : Rhône-Alpes, Loire (42), Saint-Joseph

operation Sondage (SD)

Index chronologique : Ier siècle apr. J.-C., IIe siècle apr. J.-C., IIIe siècle apr. J.-C., Antiquité romaine, Bas-Empire, IVe siècle apr. J.-C., Haut-Empire, Ve siècle apr. J.-C.

\section{AUTEURS}

CATHERINE COQUIDÉ

INRAP 